\title{
Atividade antibacteriana de extratos hidroalcoólicos de Chenopodium ambrosioides (mastruz) e Crescentia cujete (coité) em Streptococcus mutans e Staphylococcus aureus
}

\author{
Antibacterial activity of hydroalcoholic extracts of Chenopodium ambrosioides (mastruz) \\ and Crescentia cujete (coité) in Streptococcus mutans and Staphylococcus aureus \\ Actividad antibacteriana de extractos hidroalcohólicos de Chenopodium ambrosioides \\ (mastruz) y Crescentia cujete (coité) en Streptococcus mutans y Staphylococcus aureus
}

Erik Vinícius Martins Jácome ${ }^{1 *}$, Mariana Silva de Bessa ${ }^{1}$, Maria Celeste Nunes de Melo², Daniela Mendes da Veiga Pessoa ${ }^{1}$, Marquiony Marques dos Santos ${ }^{1}$, Jamile Marinho Bezerra de Oliveira Moura', Gilmara Celli Maia de Almeida ${ }^{1}$.

\begin{abstract}
RESUMO
Objetivo: Analisar a atividade antibacteriana de extratos hidroalcoólicos de folhas de mastruz, coité e de ambos associados, em cepas de Streptococcus mutans, e Staphylococcus aureus resistente e sensível à meticilina (MRSA e MSSA). Métodos: Trata-se de uma pesquisa in vitro, tendo a atividade antibacteriana determinada pela técnica de difusão em poços, onde placas de Petri com as bactérias semeadas receberam $100 \mu \mathrm{L}$ dos extratos para posterior medição dos halos de inibição. Foi utilizado como controle positivo o digluconato de clorexidina $0,12 \%$ e $2 \%$. O teste de Mann Whitney foi utilizado para verificar diferença antimicrobiana entre cada extrato e a clorexidina para cada tipo de bactéria. Resultados: O coité apresentou atividade antibacteriana expressiva sobre as bactérias $S$. aureus (MRSA e MSSA) e $S$. mutans, com efeito superior ao digluconato de clorexidina $0,12 \%$ para o MSSA $(p=0,043)$ e equivalentes para o MRSA $(p=0,197)$ e $S$. mutans $(p=0,121)$. O mastruz não desenvolveu atividade antibacteriana sobre as cepas testadas. Conclusão: O Coité apresentou efeito antibacteriano equivalente ou superior à clorexidina $0,12 \%$ nas 3 cepas testadas, mostrando-se como uma alternativa viável de antimicrobiano natural, de baixo custo e de fácil acesso pela população.
\end{abstract}

Palavras-chave: Chenopodium ambrosioides, Streptococcus mutans, Staphylococcus aureus, Antibacterianos, Clorexidina.

\begin{abstract}
Objective: To analyze the antibacterial activity of hydroalcoholic extracts of mastruz leaves, coité and both associated, in strains of Streptococcus mutans, and Staphylococcus aureus resistant and sensitive to methicillin (MRSA and MSSA). Methods: This is an in vitro research, with the antibacterial activity determined by the technique of diffusion in wells, where Petri dishes with the seeded bacteria received $100 \mu \mathrm{L}$ of the extracts for later measurement of the inhibition halos. Chlorhexidine digluconate $0.12 \%$ and $2 \%$ was used as a positive control. The Mann Whitney test was used to verify antimicrobial difference between each extract and chlorhexidine for each type of bacteria. Results: The coité showed significant antibacterial activity on the bacteria S. aureus (MRSA and MSSA) and S. mutans, with an effect superior to $0.12 \%$ chlorhexidine digluconate for MSSA $(p=0.043)$ and equivalent for MRSA $(p=0.197)$ and $S$. mutans $(p=0.121)$. The mastruz did not develop antibacterial activity on the strains tested. Conclusion: Coité showed antibacterial effect equivalent or superior to $0.12 \%$ chlorhexidine in the 3 strains tested, showing itself as a viable alternative to natural antimicrobial, of low cost and of easy access by the population.
\end{abstract}

Keywords: Chenopodium ambrosioides, Streptococcus mutans, Staphylococcus aureus, Antibacterials, Chlorhexidine.

\footnotetext{
1 Universidade do Estado do Rio Grande do Norte (UERN), Caicó - RN.

*E-mail: dentistajacome@gmail.com

2 Universidade Federal do Rio Grande do Norte (UFRN), Natal - RN.
} 


\section{RESUMEN}

Objetivo: analizar la actividad antibacteriana de extractos hidroalcohólicos de hojas de mastruz, coité y ambos asociados, en cepas de Streptococcus mutans y Staphylococcus aureus resistentes y sensibles a la meticilina (MRSA y MSSA). Métodos: Esta es una investigación in vitro, con la actividad antibacteriana determinada por la técnica de difusión en pozos, donde las placas de Petri con las bacterias sembradas recibieron $100 \mu \mathrm{L}$ de los extractos para la medición posterior de los halos de inhibición. Se usó digluconato de clorhexidina al $0,12 \%$ y al $2 \%$ como control positivo. Se usó la prueba de Mann Whitney para verificar la diferencia antimicrobiana entre cada extracto y clorhexidina para cada tipo de bacteria. Resultados: La coité mostró actividad antibacteriana significativa en las bacterias $S$. aureus (MRSA y MSSA) y $S$. mutans, con un efecto superior al digluconato de clorhexidina al $0,12 \%$ para MSSA $(p=0,043)$ y equivalente para MRSA $(p=0.197)$ y $S$. mutans $(p=0.121)$. El mastruz no desarrolló actividad antibacteriana en las cepas analizadas. Conclusión: Coité mostró un efecto antibacteriano equivalente 0 superior al $0,12 \%$ de clorhexidina en las 3 cepas analizadas, demostrando ser viable como antimicrobiano natural, con bajo costo y fácil acceso.

Palabras clave: Chenopodium ambrosioides, Streptococcus mutans, Staphylococcus aureus, Antibacterianos, Clorhexidina.

\section{INTRODUÇÃO}

A utilização de plantas medicinais para fins terapêuticos é conhecida há muito tempo e aplicada nas diferentes culturas em todo mundo (FERNANDES TM, 2004). Em 22 de junho de 2006, foi aprovada por meio do Decreto № 5.813, a Política Nacional de Plantas Medicinais e Fitoterápicos com o objetivo de permitir o acesso e uso racional das plantas e dos fitoterápicos, com eficácia, segurança e qualidade proporcionando 0 desenvolvimento desse setor (BRASIL, 2006).

A partir disso, foram estudados os efeitos fitoterápicos da Chenopodium ambrosioides, originária do México, pertencente à família Chenopodiaceae e também conhecida como mastruz ou Erva-de-Santa-Maria (BLANCKAERT I, et al., 2012). Essa espécie vem sendo usada popularmente com ação anti-helmíntica, antifúngica, antibiótica, expectorante, para dores musculares, lesões nos ossos, gripe, inflamações em geral, leishmaniose, úlceras intestinais e desordens digestivas (SÁ RD, et al., 2015).

Estudos com a espécie Crescentia cujete, pertencente à família Bignoniaceae, também vem sendo desenvolvidos. Conhecida popularmente pelo nome de coité ou cabaceira é uma planta nativa da América tropical, sendo amplamente distribuída em várias regiões tropicais de todos os continentes (ARANGO-ULLOA $\mathrm{J}$, et al., 2009). Tem sido utilizada na medicina popular para o tratamento de desordens musculoesqueléticas e metabólicas, doenças da pele, do sistema geniturinário e respiratório (TORRES-AVILEZ W, et al., 2015).

Com a ampliação da fitoterapia, muitos estudos vêm sendo realizados a fim de conseguir alguma ação antibacteriana através de extratos de plantas em bactérias, como o Staphylococcus aureus, responsável por causar infecções altamente diversas, variando de doenças agudas, como bacteremia e abscessos cutâneos, a infecções crônicas graves, frequentemente associadas a biofilmes, como a endocardite e osteomielite (LISTER JL e HORSWILL AR, 2014; HOERR V, et al., 2018).

Na microbiota oral destaca-se o Streptococcus mutans, bactéria bastante associada ao desenvolvimento de lesões de cárie que é uma doença biofilme-dependente relacionada ao consumo de carboidratos refinados na dieta da população, principalmente a sacarose, onde inicia-se com a produção de ácidos pelo metabolismo bacteriano, levando a desmineralização da superfície dentária e pode levar a perda do dente quando não tratada (MARSH PD e ZAURA E, 2017).

Diante disso, este estudo tem por objetivo analisar a atividade antibacteriana de extratos hidroalcoólicos de folhas de $C$. ambrosioides (mastruz), C. cujete (coité) e de ambos associados, em cepas de $S$. mutans e $S$. aureus resistente e sensível à meticilina (MRSA e MSSA). Assim, é possível criar novas possibilidades de pesquisa para utilização desses extratos como antimicrobianos e trazer perspectivas para a indústria farmacêutica sobre o uso comercial de preparações a base das plantas no tratamento e controle de problemas bucais e de certas infecções sistêmicas. 


\section{MÉTODOS}

\section{Coleta das Plantas e Obtenção dos Extratos Hidroalcoólicos}

As folhas do mastruz ( $C$. ambrosioides) e do coité ( $C$. cujete) foram coletadas frescas, a partir de plantas adultas selecionadas, respeitando-se o período ideal de coleta (ao amanhecer), no Sítio São Francisco localizado na cidade de Caraúbas, Rio Grande do Norte (RN), onde no mesmo cultivam-se as espécies de maneira orgânica, sem uso de agrotóxicos e fertilizantes.

Os extratos das folhas frescas de $C$. ambrosioides (extrato 1) e C. cujete (extrato 2) foram obtidos utilizando-se como agente extrator o álcool etílico absoluto PA, conforme técnica descrita por Cáceres $A$ et al. (1995) e Brasil (2010) com adaptações referentes ao tipo de solvente utilizado e temperatura do banho de aquecimento do evaporador.

Foram acondicionadas $400 \mathrm{~g}$ de folhas de cada planta em recipientes contendo $1600 \mathrm{~mL}$ de álcool etílico absoluto PA. Cada mistura foi macerada com macerador côncavo, tendo seus recipientes fechados com tampa e armazenados à temperatura ambiente por 15 dias, protegidos da luz com revestimento de papel de alumínio e com leves agitações realizadas periodicamente.

Após esse período, os extratos foram filtrados e mantidos sob refrigeração a $4^{\circ} \mathrm{C}$. Posteriormente, eles foram encaminhados para o Laboratório de Química Geral da Universidade Federal Rural do Semi-Árido (UFERSA/Campus Caraúbas) e concentrados em evaporador rotatório (Fisatom® / Mod. 803, São Paulo Brasil) a $85^{\circ} \mathrm{C}$ com bomba de vácuo para a evaporação do solvente. Ao final dessa etapa, dois tipos de extratos foram produzidos.

Posteriormente, um terço dos extratos 1 e 2 foram separados e misturados em um frasco âmbar de 300 $\mathrm{mL}$ esterilizado gerando um terceiro extrato combinado (extrato 3 ). Nesse sentido, foram produzidos 3 extratos a serem testados com as bactérias.

\section{Amostras Bacterianas}

As bactérias utilizadas no estudo são cepas padrões, sendo estas o Streptococcus mutans (ATCC 55676), Staphylococcus aureus resistente à meticilina (ATCC BMB 9393) e sensível à meticilina (ATCC 25923). Elas foram cedidas em eppendorf contendo TSB adicionado de 20,0\% de glicerol pelo Laboratório de Bacteriologia Médica da Universidade Federal do Rio Grande do Norte (UFRN).

Com base em normatizações descritas pela ANVISA (2004) e CLSI (2013), foram realizados os seguintes procedimentos: cultivo, confirmação de crescimento e identificação das bactérias. Para a avaliação da atividade antibacteriana as linhagens foram cultivadas em caldo nutritivo (Caldo Nutriente) e incubadas a $37^{\circ}$ $\mathrm{C}$ por 18 horas em aerobiose. Em seguida, foram preparadas suspensões de cultura diluídas em solução salina $0,85 \%$, sendo que as suspensões obtidas tiveram a turvação ajustadas por comparação visual à suspensão padrão 0,5 da escala de McFarland, conforme recomendações do CLSI (2013).

\section{Determinação da Atividade Antimicrobiana - Técnica de Difusão em Poços ou "Template"}

A determinação da atividade antibacteriana foi realizada pela técnica de difusão em poços ou "template" conforme atualizações da CLSI (2018) e recomendações da ANVISA / Fundação Oswaldo Cruz, Brasil (2010). Todos os testes foram realizados em triplicata.

Um total de 18 placas de Petri com ágar Mueller-Hinton foram preparadas, nas quais, após solidificação dos meios, foram realizadas quatro perfurações (poços) de $6 \mathrm{~mm}$ de diâmetro por placa com auxílio de cilindros de vidro estéreis (BRASIL, 2010; CLSI, 2018).

Em seguida foram inoculadas sobre a superfície dos meios, com swabs estéreis, as três cepas bacterianas, sendo cada uma das cepas semeadas em 6 placas distintas, uma vez que a distribuição dos extratos foi feita em triplicata para melhor confiabilidade dos dados, sendo 3 placas utilizando clorexidina $0,12 \%$ e 3 placas contendo clorexidina $2 \%$. Cada placa continha os 3 extratos testados (Coité, Mastruz e Mastruz + Coité). 
Nos poços foram distribuídos $100 \mu \mathrm{L}$ dos extratos hidroalcoólicos, sendo que cada poço foi preenchido com um extrato diferente e com uma das substâncias do controle positivo (digluconato de clorexidina $0,12 \%$ ou $2 \%$ ). A clorexidina foi utilizada como controle positivo em duas concentrações para ser possível comparar com seu uso intra-oral $(0,12 \%)$ e extra-oral em ambiente hospitalar $(2 \%)$.

Posteriormente, as placas foram mantidas em estufa bacteriológica à $37^{\circ} \mathrm{C}$ e os halos de inibição foram medidos em milímetros, com auxílio de uma régua milimetrada após 24 horas de incubação. No total, nove placas continham em um dos poços a clorexidina $0,12 \%$ e 9 placas a clorexidina $2 \%$, como controles positivos.

\section{Análise dos Dados}

Para análise dos dados, realizou-se a estatística descritiva com apresentação das medidas de tendência central (média e mediana) e variabilidade (desvio padrão e quartis 25 e 75) dos halos de inibição produzidos pelos extratos e pelo controle positivo em cada tipo de bactéria testada.

Considerando a amostra pequena do estudo, optou-se por análise inferencial para dados não paramétricos, sendo o teste de Mann Whitney utilizado para verificar se existia diferença significativa entre os halos de inibição de cada tipo de extrato (mastruz, coité e mastruz + coité) e o controle positivo (digluconato de clorexidina), em relação a cada uma das cepas testadas.

O teste de Mann Whitney também foi utilizado para verificar se havia diferença significativa entre clorexidina $0,12 \%$ e clorexidina $2 \%$ para cada tipo bacteriano. Em todas as análises, foi utilizado o Statistical Package for the Social Sciences (SPSS) $20.0 \AA$, considerando nível de significância de $5 \%$.

\section{RESULTADOS}

A atividade antimicrobiana é caracterizada pela formação de zonas de inibição de crescimento ao redor dos poços (com as diferentes substâncias testadas) nos meios que foram cultivados por bactérias. A zona clara formada mostra a atividade inibitória do crescimento bacteriano por compostos antimicrobianos presentes nas substâncias (Figura 1).

As três linhagens bacterianas testadas neste estudo (Streptococcus mutans, Staphylococcus aureus resistente à meticilina - MRSA e Staphylococcus aureus sensível à meticilina - MSSA), apresentaram sensibilidade aos extratos hidroalcoólicos do coité (C. cujete) isoladamente e do coité associado ao mastruz (C. ambrosioides), (Tabela 1).

Nas placas em que foi utilizado o digluconato de clorexidina $2 \%$ como controle positivo, também foi evidenciada atividade antimicrobiana dos extratos hidroalcoólicos do coité e do mastruz + coité sobre as três bactérias testadas (Tabela 2). Na análise comparativa entre as médias dos halos de inibição dos digluconatos de clorexidina $0,12 \%$ e $2 \%$, observa-se que a segunda se sobressaiu a primeira em relação ao maior efeito antimicrobiano sobre as três bactérias estudadas.

O mastruz isoladamente não apresentou efeito sobre nenhuma das bactérias testadas, sem formação de halos de inibição. Diante disso, a ação antimicrobiana quando utilizado o extrato 3 (Coité e Mastruz associados) é decorrente apenas das propriedades do Coité, sendo este resultado evidenciado pela ausência de diferença significativa entre os halos do Coité isoladamente e associado ao mastruz, com valores de $p$ entre 0,346 e 1,000, considerando cada uma das bactérias para os dois grupos de controle positivo (digluconato de clorexidina $0,12 \%$ e $2 \%$ ). Diante disso, a análise inferencial bivariada da pesquisa foi direcionada para a comparação entre Coité e Clorexidina $(0,12 \%$ e $2 \%)$ em cada uma das bactérias utilizadas no estudo (Tabela 3).

Além disso, foi analisada se havia diferença significativa entre os halos de inibição dos dois controles positivos testados, medidos em milímetros. A Clorexidina $2 \%$ apresentou halos significativamente maiores para o $S$. mutans $(p=0,046)$ e o MRSA $(p=0,043)$, enquanto para o MSSA não houve diferença significativa entre as Clorexidinas $0,12 \%$ e $2 \%(p=0,513)$. 
Figura 1 - Halos de inibição dos extratos hidroalcoólicos do mastruz (A), coité (B), mastruz com coité (C) e Clorexidina (D) sobre as linhagens de Streptococcus mutans ATCC 55676 (E), MRSA ATCC BMB 9393 (F) e MSSA ATCC $25923(\mathrm{G})$.

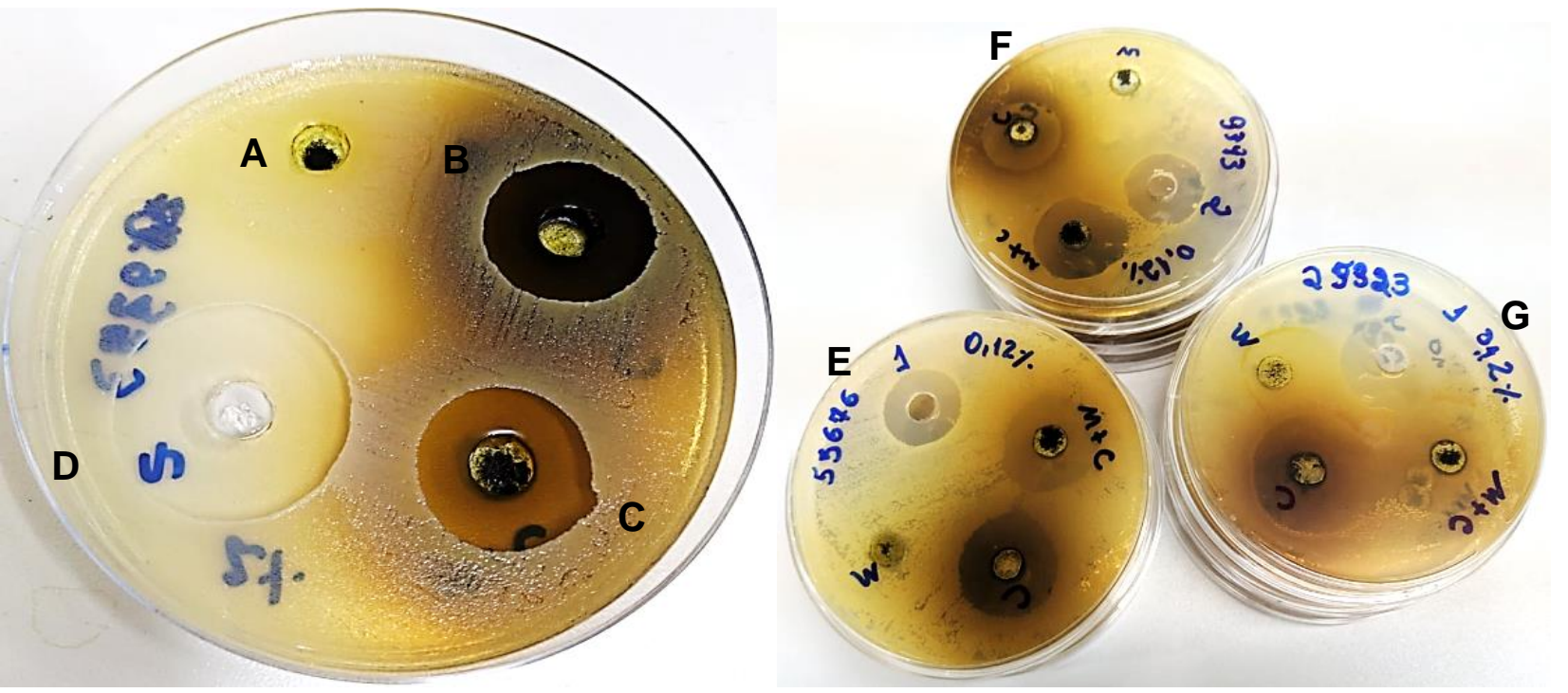

Fonte: Jácome EVM, et al., 2020

Tabela 1 - Estatística descritiva da ação antimicrobiana dos extratos, para cada tipo de bactéria, utilizando o digluconato de clorexidina $0,12 \%$ como controle positivo.

\begin{tabular}{|c|c|c|c|c|c|c|c|c|c|}
\hline \multirow{3}{*}{$\begin{array}{l}\text { Tipo de } \\
\text { bactéria }\end{array}$} & \multicolumn{9}{|c|}{ Halo de inibição (em milímetros) } \\
\hline & \multicolumn{3}{|c|}{ Coité } & \multicolumn{3}{|c|}{ Mastruz + coité } & \multicolumn{3}{|c|}{ Clorexidina $0,12 \%$} \\
\hline & $\begin{array}{l}\text { Média } \\
\text { (DP) }\end{array}$ & $\begin{array}{l}\text { IC- } \\
95 \%\end{array}$ & $\begin{array}{c}\text { Mediana } \\
\text { (Q25-Q75) }\end{array}$ & $\begin{array}{c}\text { Média } \\
\text { (DP) }\end{array}$ & $\begin{array}{l}\text { IC- } \\
95 \%\end{array}$ & $\begin{array}{c}\text { Mediana } \\
(Q 25-Q 75)\end{array}$ & $\begin{array}{c}\text { Média } \\
\text { (DP) }\end{array}$ & $\begin{array}{l}\text { IC- } \\
95 \%\end{array}$ & $\begin{array}{c}\text { Mediana } \\
\text { (Q25-Q75) }\end{array}$ \\
\hline $\begin{array}{l}\text { Streptococcus } \\
\text { mutans }\end{array}$ & $\begin{array}{l}25,3 \\
(2,5)\end{array}$ & $\begin{array}{l}19,1- \\
31,6\end{array}$ & $\begin{array}{c}25,0 \\
(24,0-26,5)\end{array}$ & $\begin{array}{l}25,0 \\
(1,0)\end{array}$ & $\begin{array}{l}22,5- \\
27,5\end{array}$ & $\begin{array}{c}25,0 \\
(24,5-25,5)\end{array}$ & $\begin{array}{l}20,7 \\
(2,9)\end{array}$ & $\begin{array}{l}13,5- \\
27,8\end{array}$ & $\begin{array}{c}19,0 \\
(19,0-21,5)\end{array}$ \\
\hline MRSA & $\begin{array}{l}21,3 \\
(0,6)\end{array}$ & $\begin{array}{l}19,9- \\
22,8\end{array}$ & $\begin{array}{c}21,0 \\
(21,0-21,5)\end{array}$ & $\begin{array}{l}23,3 \\
(2,9)\end{array}$ & $\begin{array}{l}16,2- \\
30,5\end{array}$ & $\begin{array}{c}25,0 \\
(22,5-25,0)\end{array}$ & $\begin{array}{l}20,7 \\
(0,6)\end{array}$ & $\begin{array}{l}19,2- \\
22,1\end{array}$ & $\begin{array}{c}21,0 \\
(20,5-21,0)\end{array}$ \\
\hline MSSA & $\begin{array}{l}31,3 \\
(0,6)\end{array}$ & $\begin{array}{c}29,9- \\
32,8\end{array}$ & $\begin{array}{c}31,00 \\
(31,0-31,5)\end{array}$ & $\begin{array}{l}29,7 \\
(0,6)\end{array}$ & $\begin{array}{c}28,2- \\
31,1\end{array}$ & $\begin{array}{c}30,0 \\
(29,5-31,1)\end{array}$ & $\begin{array}{l}25,7 \\
(1,1)\end{array}$ & $\begin{array}{l}22,8- \\
28,5\end{array}$ & $\begin{array}{c}25,0 \\
(25,0-26,0)\end{array}$ \\
\hline
\end{tabular}

Legenda: IC= Intervalo de Confiança

Fonte: Jácome EVM, et al., 2020

Tabela 2 - Estatística descritiva da ação antimicrobiana dos extratos, para cada tipo de bactéria, utilizando o digluconato de clorexidina $2 \%$ como controle positivo.

\begin{tabular}{|c|c|c|c|c|c|c|c|c|c|}
\hline \multirow[b]{3}{*}{ Tipo de bactéria } & \multicolumn{9}{|c|}{ Halo de inibição (em milímetros) } \\
\hline & \multicolumn{3}{|c|}{ Coité } & \multicolumn{3}{|c|}{ Mastruz + coité } & \multicolumn{3}{|c|}{ Clorexidina $2 \%$} \\
\hline & $\begin{array}{c}\text { Média } \\
\text { (DP) }\end{array}$ & $\begin{array}{l}\text { IC- } \\
95 \%\end{array}$ & $\begin{array}{c}\text { Mediana } \\
\text { (Q25-Q75) }\end{array}$ & $\begin{array}{c}\text { Média } \\
\text { (DP) }\end{array}$ & $\begin{array}{l}\text { IC- } \\
95 \%\end{array}$ & $\begin{array}{c}\text { Mediana } \\
(\text { Q25-Q75) }\end{array}$ & $\begin{array}{c}\text { Média } \\
\text { (DP) }\end{array}$ & $\begin{array}{l}\text { IC- } \\
95 \%\end{array}$ & $\begin{array}{c}\text { Mediana } \\
\text { (Q25-Q75) }\end{array}$ \\
\hline $\begin{array}{l}\text { Streptococcus } \\
\text { mutans }\end{array}$ & $\begin{array}{l}24,7 \\
(3,0)\end{array}$ & $\begin{array}{l}17,1- \\
32,2\end{array}$ & $\begin{array}{c}24,0 \\
(23,0-26,0)\end{array}$ & $\begin{array}{l}24,3 \\
(1,1)\end{array}$ & $\begin{array}{l}21,5- \\
27,2\end{array}$ & $\begin{array}{c}25,0 \\
(24,0-25,0)\end{array}$ & $\begin{array}{c}28 \\
(1,0)\end{array}$ & $\begin{array}{l}25,5- \\
30,5\end{array}$ & $\begin{array}{c}28,0 \\
(27,5-28,5)\end{array}$ \\
\hline MRSA & $\begin{array}{l}21,7 \\
(0,6)\end{array}$ & $\begin{array}{l}20,2- \\
23,1\end{array}$ & $\begin{array}{c}22,0 \\
(21,5-22,0)\end{array}$ & $\begin{array}{c}21,00 \\
(1,0)\end{array}$ & $\begin{array}{l}18,5- \\
23,5\end{array}$ & $\begin{array}{c}21,0 \\
(20,5-21,0)\end{array}$ & $\begin{array}{l}27,3 \\
(0,6)\end{array}$ & $\begin{array}{l}25,9- \\
28,8\end{array}$ & $\begin{array}{c}27,0 \\
(27,0-27,5)\end{array}$ \\
\hline MSSA & $\begin{array}{l}31,0 \\
(5,0)\end{array}$ & $\begin{array}{l}18,6- \\
43,4\end{array}$ & $\begin{array}{c}31,00 \\
(28,5-33,5)\end{array}$ & $\begin{array}{c}32 \\
(3,6)\end{array}$ & $\begin{array}{l}23,0- \\
40,9\end{array}$ & $\begin{array}{c}33,0 \\
(30,5-34,0)\end{array}$ & $\begin{array}{l}26,7 \\
(9,1)\end{array}$ & $\begin{array}{l}4,1- \\
49,2\end{array}$ & $\begin{array}{c}28,0 \\
(22,5-31,5)\end{array}$ \\
\hline
\end{tabular}

Legenda: IC= Intervalo de Confiança. Fonte: Jácome EVM, et al., 2020 
Tabela 3 - Comparação da ação antimicrobiana entre Coité e Clorexidina (0,12\% e $2 \%)$ sobre Streptococcus mutans (ATCC 55676), MRSA (ATCC BMB 9393) e MSSA (ATCC 25923).

\begin{tabular}{|c|c|c|c|c|c|c|}
\hline \multirow{2}{*}{ Tipo de bactéria } & Coité & $\begin{array}{c}\text { Clorexidina } \\
0,12 \%\end{array}$ & \multirow{2}{*}{ P-valor } & Coité & $\begin{array}{c}\text { Clorexidina } \\
2 \% \\
\end{array}$ & \multirow{2}{*}{ P-valor } \\
\hline & $\begin{array}{l}\text { Mediana } \\
\text { (Q25-q75) }\end{array}$ & $\begin{array}{l}\text { Mediana } \\
(q 25-q 75)\end{array}$ & & $\begin{array}{l}\text { Mediana } \\
(q 25-q 75)\end{array}$ & $\begin{array}{l}\text { Mediana } \\
(q 25-q 75)\end{array}$ & \\
\hline $\begin{array}{l}\text { Streptococcus } \\
\text { mutans }\end{array}$ & $\begin{array}{c}25,0 \\
(24,0-26,5)\end{array}$ & $\begin{array}{c}19,0 \\
(19,0-21,5)\end{array}$ & 0,121 & $\begin{array}{c}24,0 \\
(23,0-26,0)\end{array}$ & $\begin{array}{c}28,0 \\
(27,5-28,5)\end{array}$ & 0,184 \\
\hline MRSA & $\begin{array}{c}21,0 \\
(21,0-21,5)\end{array}$ & $\begin{array}{c}21,0 \\
(20,5-21,0)\end{array}$ & 0,197 & $\begin{array}{c}22,0 \\
(21,5-22,0)\end{array}$ & $\begin{array}{c}27,0 \\
(27,0-27,5)\end{array}$ & 0,043 \\
\hline MSSA & $\begin{array}{c}31,00 \\
(31,0-31,5)\end{array}$ & $\begin{array}{c}25,0 \\
(25,0-26,0)\end{array}$ & 0,043 & $\begin{array}{c}31,00 \\
(28,5-33,5)\end{array}$ & $\begin{array}{c}28,0 \\
(22,5-31,5)\end{array}$ & 0,513 \\
\hline
\end{tabular}

Legenda: *Teste de Mann-Whitney

Fonte: Jácome EVM, et al., 2020.

\section{DISCUSSÃO}

Nos últimos anos observam-se cada vez mais casos de resistência bacteriana aos antibióticos utilizados nos serviços de saúde. Esse fato é considerado um problema de saúde pública com maior relevância clínica, já que dificulta o controle das doenças infecciosas na população; favorece o aumento da morbimortalidade; diminui a eficácia terapêutica; promove a transmissão de infecções a outros indivíduos; traz riscos à segurança do paciente e aumenta os custos para os serviços de saúde (MONTEMAYOR JCG, et al., 2014).

Entretanto, no período de 2007 a 2016 foram indexados na Scielo 853 artigos sobre testes com plantas medicinais, sendo que somente 38 (4,4\%) abordavam a atividade antimicrobiana (AMPARO TR, et al., 2018). Isso mostra que apesar da importância atual que se tem de buscar alternativas para o controle microbiano, a produção científica direcionada para essa finalidade ainda se encontra baixa, visto o potencial de várias espécies vegetais encontradas no Brasil.

Dentre essas espécies destaca-se o Chenopodium ambrosioides (mastruz), que vem sendo utilizado empiricamente no tratamento de várias afecções, inclusive como anti-séptico oral (BIESKI IGC, et al., 2015). Estudos destacam sua eficácia como antifúngico (JESUS RS, et al., 2018), cicatrizante e anti-inflamatório (TRIVELLATO LG, et al., 2013), tendo grande abundância dos compostos kaempferol e quercetina, pertencentes ao grupo dos flavonoides, sugestivos de atividade antibacteriana (GUPTA B e HUANG B, 2014).

Porém, no presente estudo não houve efeito antimicrobiano sobre as bactérias testadas. É possível que o resultado negativo seja atribuído a concentração utilizada na pesquisa, forma de utilização do extrato que tenha resultado em perda de atividade dos componentes antimicrobianos ou ausência de teste em meio líquido que poderia ser mais favorável para identificar o efeito sobre as bactérias testadas.

Além do Chenopodium ambrosioides, foi utilizado no estudo Crescentia cujete, o coité, planta esta que se destaca na medicina popular no tratamento de diversas enfermidades. Suas folhas frescas são usadas topicamente para a cicatrização de feridas, enquanto que as folhas em pó são usadas para tratar dores de cabeça, internamente como diurético e no tratamento de hematomas e tumores (PARVIN MS, et al., 2015). Porém, estudos que testam sua atividade antimicrobiana ainda são escassos. Nesse sentido, o presente estudo verificou efeito antimicrobiano do Coité semelhante a clorexidina para $S$. mutans o que indica um campo aberto de pesquisa para verificar seu uso como solução intraoral em indivíduos com alta atividade de cárie dentária e que necessitem do uso de antimicrobiano como coadjuvante no controle da infecção.

A comparação do efeito do Coité com o digluconato de clorexidina é importante, uma vez que este é considerado o padrão ouro como antimicrobiano para uso odontológico, dada sua alta substantividade e espectro de ação sobre as bactérias orais, caracterizando-se como uma substância química que possui ação antibacteriana contra bactérias Gram-positivas e Gram-negativas com vários estudos que relatam sua eficácia contra o S. mutans, agente relacionado à cárie dentária em estágios iniciais e avançados (DE FREITASFERNANDES FS, et al., 2015). 
Moreira ACA et al. (2010) demonstraram a eficácia da clorexidina 0,12\% e 0,2\% (usadas para bochechos intraoral como coadjuvante a higienização mecânica), onde as duas concentrações inibiram o crescimento de bactérias como o S. aureus, Enterococcus faecalis, Pseudomonas aeruginosa e $S$. mutans, resultando em uma melhor redução dos microrganismos na saliva. Sendo assim, a clorexidina é eficaz no controle do biofilme dentário, atuando no controle e tratamento de doenças bucais.

A depender de sua concentração, a clorexidina possui efeitos diferentes sobre as bactérias, como traz o estudo de Srinivas A, et al. (2015) que em baixas concentrações ela possui efeito bacteriostático, causando alteração no equilíbrio osmótico da célula bacteriana; e em altas concentrações é bactericida, causando a fragmentação de seus conteúdos citoplasmáticos. A clorexidina $2 \%$ é comumente utilizada para degermação em procedimentos cirúrgicos e para controle de contaminação cruzada (CUNHA ÉR DA, et al., 2011), enquanto a $0,12 \%$ para diminuir carga microbiana oral antes e após cirurgias orais (MOREIRA ACA, et al., 2010).

Contudo, apesar da clorexidina ser amplamente utilizada na Odontologia (solução antimicrobiana padrão ouro) e em ambiente hospitalar, a busca de substâncias fitoterápicas alternativas com ação antimicrobiana adequada e mínimos efeitos adversos para pele e mucosa é salutar. Nesse sentido, a clorexidina apresenta efeitos adversos locais, além de serem relatados efeitos alergênicos e reportados desenvolvimento crescente de resistência bacteriana, com destaque o S. aureus (PEGORARO J, et al., 2015; BARBOSA A, et al., 2019).

Dentre os efeitos adversos da clorexidina a $0,12 \%$ na cavidade oral, destacam-se alteração na coloração dos elementos dentários, alteração do paladar, queimaduras no tecido mole, xerostomia, lesões descamativas, ulcerações na mucosa e gosto residual desagradável na boca (PEGORARO J, et al., 2015).

Já o alerta sobre reações alérgicas raras, porém graves, com a Clorexidina utilizada como antisséptico na pele, foi dado por meio de um Comunicado de Segurança de Medicamentos ("FDA Drug Safety Communication"), (U.S. FOOD AND DRUG ADMINISTRATION, 2017). Os relatos de reações alérgicas graves a produtos que contém a substância em sua composição aumentaram consideravelmente nos últimos anos, sendo que os sintomas relatados (como o chiado ou dificuldade para respirar, inchaço do rosto e urticária) podem progredir rapidamente para sintomas mais graves, como a erupção grave ou choque, que é uma condição com risco à vida que ocorre quando o corpo não está recebendo fluxo sanguíneo suficiente.

Assim, como o Coité apresentou halos de inibição equivalentes aos apresentados pela clorexidina, há um caminho viável do uso de Crescentia cujete como alternativa de antimicrobiano intra e extraoral. Essa questão pode ser vislumbrada por ser um extrato relativamente não-tóxico, como demonstrado no estudo de Anwuchaepe AU, et al. (2017) que avaliou a toxicidade aguda do coité por via oral em camundongos, e não foram reveladas reações tóxicas ou letalidade em nenhuma das doses selecionadas, com LD50 do extrato bruto acima de $5000 \mathrm{mg} / \mathrm{kg}$. Este é o primeiro estudo a relatar a toxicidade aguda de folhas de C. cujete, sugerindo que essa parte da planta pode ser segura para consumo humano.

No que concerne a Concentração Inibitória Mínima (CIM) para C. Cujete, esta foi verificada no estudo de Mahbub KR, et al. (2011), sobre algumas bactérias patogênicas, dentre elas o S. aureus (ATCC 25922), na qual o extrato etanólico do pó de folhas da planta inibiu o crescimento da bactéria com a concentração de $4.500 \mu \mathrm{g} / \mathrm{ml}$. Estudos que avaliam a CIM de folhas frescas da planta, a partir da metodologia empregada nesta pesquisa da preparação do extrato, não foram encontrados na literatura. Nesse sentido, diante do efeito antimicrobiano do Coité encontrado, é salutar destacar a necessidade de estudos que testem a CIM em condições similares de obtenção do extrato da presente pesquisa, uma vez que a desidratação do material vegetal pode levar a alterações ou perdas de compostos químicos da planta.

As ações benéficas apresentadas pelas folhas do coité podem estar associadas a compostos fitoquímicos como flavonóides, saponinas e taninos, sendo estes influenciados por diferenças na origem da planta, localização geográfica, idade da planta e processo de extração (HASANAH U, et al., 2017). Os flavonóides têm um papel na proteção das células humanas contra os danos dos radicais livres (SYAEFUDIN, et al., 2014) e também podem atuar como antibacterianos (PARVIN MS, et al., 2015). As saponinas são conhecidas pelo seu pontencial como antibióticos naturais e anti-inflamatórios (EJELONU BC, et al., 2011). Já os taninos desempenham um papel na cicatrização de feridas e previnem infecções bacterianas (OGBUAGU MN, 2008). 
O extrato de coité associado a nanopartículas de prata foi testado no estudo de Prabukumar S et al. (2018), inibindo progressivamente o crescimento de bactérias Gram-positivas ( $R$. rhodochrous, $B$. subtilis, $S$. epidermidis e M. smegmatis) e Gram-negativas (S. typhi, S. flexneri e V. cholerae) nas concentrações de 25$100 \mu \mathrm{g}$. As hipóteses levantadas pelo estudo se referem a reação entre os grupos tiol, fósforo e enxofre do extrato, que inibe a reação em cadeia respiratória, a divisão celular e a replicação bacteriana, levando à morte dos patógenos.

Esses achados sugerem o amplo espectro do coité, inclusive sobre algumas cepas de Gram-negativas, as quais predominam no biofilme periodontopatogênico. Assim, analisar o efeito do Coité sobre bactérias associadas à doença periodontal é uma caminho de pesquisa relevante, com destaque para Porphyromonas gingivalis, Tannerella forsythia, Prevotella intermedia, Aggregatibacter actinomycetemcomitans.

Ainda sobre atividade antimicrobiana do coité, Hasanah U, et al. (2017) verificaram que o extrato etanólico das folhas pode inibir o crescimento de Staphylococcus aureus e Escherichia coli. Assim como foi observado por Hartati I et al. (2011) que o extrato etanólico inibiu o crescimento de S. aureus, E.coli e o fungo Candida albicans em uma concentração de $10 \%$. Tais estudos corroboram os achados desta pesquisa, na qual o extrato hidroalcoólico da planta inibiu o crescimento das duas cepas testadas de $S$. aureus, destacando-se o MRSA como patógeno associado a infecções secundárias ou sistêmicas em ambiente hospitalar, com alto potencial de morbimortalidade (NELSON RE, et al., 2019).

Diante do efeito do coité sobre bactérias patogênicas encontradas em ambiente hospitalar, esse extrato pode ser uma alternativa como degermante cirúrgico. No presente estudo, a clorexidina $2 \%$ apresentou resultado equivalente ao Coité em duas (MSSA e S. mutans) das três linhagens bacterianas testadas. Vale salientar que a clorexidina é uma das soluções mais utilizadas nos estabelecimentos de saúde brasileiros para o procedimento da degermação cirúrgica das mãos e antebraços (CUNHA ÉR DA, et al., 2011).

Diante dos resultados positivos do coité no presente estudo, faz-se necessário testá-lo com outras cepas microbianas orais, especialmente as selvagens, bem como buscar a Concentração Inibitória Mínima em meio líquido. Caso outros estudos corroborem o seu potencial microbiano, é possível vislumbrar o uso do coité como solução intraoral em pacientes vulneráveis, hospitalizados, internados em Unidades de Terapia Intensiva, com limitações motoras e outras situações que demandem uso de antimicrobianos como coadjuvante para controle de infecções orais e sistêmicas, uma vez que a cavidade oral é porta de entrada de agentes potencialmente patogênicos, especialmente em situações de alteração da microbiota residente (SANTOS PSS, et al., 2013).

Apesar dos resultados promissores encontrados, existe necessidade de iniciar e/ou ampliar o desenvolvimento de estudos in vitro, in situ, em animais e ensaios clínicos em seres humanos com intuito de elucidar sobre estabilidade dos componentes antimicrobianos (flavonóides e taninos), toxicidade, Concentração Inibitória Mínima frente a cepas selvagens e efeitos adversos de Crescentia cujete. Caso os resultados se apresentem favoráveis, pode ser avaliada a incorporação do extrato a dentifrícios e colutórios. Além disso, pode ser uma alternativa de antisséptico para pele e mucosa e de agente desinfetante de superfícies.

\section{CONCLUSÃO}

Estudos com plantas medicinais são importantes devido à diversidade estrutural de compostos químicos que elas apresentam, que possuem potencial para o desenvolvimento de produtos com finalidades terapêuticas úteis para a manutenção da saúde e da qualidade de vida. O extrato hidroalcoólico de folhas frescas da espécie Crescentia cujete apresentou atividade antibacteriana expressiva sobre as bactérias Staphylococcus aureus (MRSA e MSSA) e Streptococcus mutans, com efeito superior ao digluconato de clorexidina $0,12 \%$ para o MSSA e equivalentes para o MRSA e $S$. mutans. É importante destacar que há escassez de dados sobre o efeito desse extrato sobre o $S$. mutans, bactéria de importância odontológica devido sua associação aos biofilmes cariogênicos. 


\section{AGRADECIMENTOS}

Agradecimentos ao Prof. Daniel Freitas Freire Martins pela ajuda e disposição de equipamentos para a preparação dos extratos hidroalcoólicos vegetais por meio da Universidade Federal Rural do Semi-Árido (UFERSA/Campus Caraúbas).

\section{REFERÊNCIAS}

1. AMPARO TR, et al. Métodos para avaliação in vitro da atividade antimicrobiana de plantas medicinais: a necessidade da padronização. Infarma - Ciências Farmacêuticas, 2018; 30: 50-59.

2. ANVISA. Detecção e identificação de bactérias de importância médica - Módulo 5. Brasília: Ministério da Saúde, 2004; 95p.

3. ANWUCHAEPE AU, et al. Evaluation of the in vivo antioxidant, toxicological and chromatographical profiling of leaf extract and fractions of Crescentia cujete Linn. (Bignoniaceae). Asian Pacific Journal of Health Sciences, 2017 ; 4: 4354.

4. ARANGO-ULLOA J, et al. Diversity of the calabash tree (Crescentia cujete L.) in Colombia. Agroforestry Systems, 2009; 76: 543-553.

5. BARBOSA A, et al. Diminuição da susceptibilidade à clorexidina: revisão sistemática. Journal of Infection Control, 2019; 8: 24-30.

6. BIESKI IGC, et al. Ethnobotanical study of medicinal plants by population of Valley of Juruena Region, Legal Amazon, Mato Grosso, Brazil. Journal of Ethnopharmacology, 2015; 173: 383-423.

7. BLANCKAERT I, et al. Ethnobotanical, morphological, phytochemical and molecular evidence for the incipient domestication of Epazote (Chenopodium ambrosioides L.: Chenopodiaceae) in a semi-arid region of Mexico. Genetic Resources and Crop Evolution, 2012; 59: 557-573.

8. BRASIL. Farmacopeia brasileira. 5 ed. Brasília: ANVISA/Fundação Oswaldo Cruz, 2010; 2: 904p.

9. BRASIL. Ministério da Saúde. A fitoterapia no SUS e o programa de pesquisas de plantas medicinais da central de medicamentos. Brasília: 2006; 148p.

10. CÁCERES A, et al. Antigonorrhoeal activity of plants used in Guatemala for the treatment of sexually transmitted diseases. Journal of Ethnopharmacology, 1995; 48: 85-88.

11. CLINICAL AND LABORATORY STANDARDS INSTITUTE (CLSI). Performance standards for antimicrobial susceptibility testing; twenty-third informational supplement (CLSI Document M100-S23). 2013; 206p.

12. CLINICAL AND LABORATORY STANDARDS INSTITUTE (CLSI). Performance standards for antimicrobial disk susceptibility tests. 13th ed. CLSI standard M02. Wayne, PA: Clinical and Laboratory Standards Institute. 2018; 71p.

13. CUNHA ÉR DA, et al. Eficácia de três métodos de degermação das mãos utilizando gluconato de clorexidina degermante (GCH 2\%). Revista da Escola de Enfermagem da USP, 2011; 45: 1440-1445.

14. DE FREITAS-FERNANDES FS, et al. Effect of chlorhexidine gel in mentally handicapped children highly infected with Streptococcus mutans. Pesquisa Brasileira em Odontopediatria e Clínica Integrada, 2015; 15: 49-55.

15. EJELONU BC, et al. The chemical constituents of calabash (Crescentia cujete). African Journal of Biotechnology, 2011; 10: 19631-19636.

16. FERNANDES TM. Plantas medicinais: memória da ciência no Brasil. Rio de Janeiro: FIOCRUZ, 2004; 260p.

17. GUPTA B, HUANG B. Mechanism of salinity tolerance in plants: physiological, biochemical, and molecular characterization. International Journal of Genomics, 2014; 2014: 1-18.

18. HARTATI I, et al. Uji aktivitas antimikroba ekstrak daun Crescentia cujete L terhadap Staphylococcus aureus, Escherichia coli dan Candida albicans. Research and Community Service Institute Universitas Negeri Makassar, 2011: 425-427.

19. HASANAH U, et al. Antibacterial activity of ethanol extract from stem bark and leaves of berenuk (Crescentia cujete L.). Current Biochemistry, 2017; 4: 1-14.

20. HOERR V, et al. S. aureus endocarditis: clinical aspects and experimental approaches. International Journal of Medical Microbiology, 2018; 308: 640-652.

21. JESUS RS, et al. In vitro antimicrobial and antimycobacterial activity and HPLC-DAD screening of phenolics from Chenopodium ambrosioides L. Brazilian Journal of Microbiology, 2018; 49: 296-302.

22. LISTER JL, HORSWILL AR. Staphylococcus aureus biofilms: recent developments in biofilm dispersal. Frontiers in Cellular and Infection Microbiology, 2014; 4: 1-9.

23. MAHBUB KR, et al. In vitro antibacterial activity of Crescentia cujete and Moringa oleifera. Bangladesh Research Publications Journal, 2011; 5: 337-343.

24. MARSH PD, ZAURA E. Dental biofilm: ecological interactions in health and disease. Journal of Clinical Periodontology, 2017; 44: 12-22.

25. MONTEMAYOR JCG, et al. Impacto de los movimientos migratorios en la resistencia bacteriana a los antibióticos. Revista Española de Salud Pública, 2014; 88: 829-837.

26. MOREIRA ACA, et al. Avaliação in vitro da atividade antimicrobiana de antissépticos bucais. Revista de Ciências Médicas e Biológicas, 2010; 8: 153-161.

27. NELSON RE, et al. Methicillin-resistant Staphylococcus aureus colonization and pre- and post-hospital discharge infection risk. Clin Infect Dis, 2019; 68: 545-553. 
28. OGBUAGU MN. The nutritive and anti-nutritive compositions of calabash (Crescentia cujete) fruit pulp. Journal of Animal and Veterinary Advances, 2008; 7: 1069-1072.

29. PARVIN MS, et al. Evaluation of in vitro anti-inflammatory and antibacterial potential of Crescentia cujete leaves and stem bark pharmacology and toxicology. BMC Research Notes, 2015; 8: 1-7.

30. PEGORARO J, et al. Efeitos adversos do gluconato de clorexidina à $0,12 \%$. Journal of Oral Investigations, $2015 ; 3$ : 33p.

31. PRABUKUMAR S, et al. One pot green fabrication of metallic silver nanoscale materials using Crescentia cujete L. and assessment of their bactericidal activity. IET Nanobiotechnology, 2018; 12: 505-508.

32. SÁ RD, et al. Óleo essencial de Chenopodium ambrosioides L.: estado da arte. Revista de Ciências Farmacêuticas Básica e Aplicada, 2015; 36: 267-276.

33. SANTOS PSS, et al. Impacto da remoção de biofilme lingual em pacientes sob ventilação mecânica. Revista Brasileira de Terapia Intensiva, 2013; 25: 44-48.

34. SRINIVAS A, et al. Comparison of the efficacy of chlorhexidine gluconate versus povidone iodine as preoperative skin preparation for the prevention of surgical site infections in clean-contaminated upper abdominal surgeries. Surgery Today, 2015; 45: 1378-1384.

35. SYAEFUDIN, et al. Antioxidant activity of flavonoid from Guazuma ulmifolia La ink. leaves and apoptosis induction in yeast cells. Journal of Biological Sciences, 2014; 14: 305-310.

36. TORRES-AVILEZ W, et al. Medicinal plant knowledge in Caribbean Basin: a comparative study of Afrocaribbean, Amerindian and Mestizo communities. Journal of Ethnobiology and Ethnomedicine, 2015; 11: 1-11.

37. TRIVELLATO LG, et al. From popular use to pharmacological validation: a study of the anti-inflammatory, antinociceptive and healing effects of Chenopodium ambrosioides extract. Journal of Ethnopharmacology, 2013; 145: 127-138.

38. U.S. FOOD AND DRUG ADMINISTRATION. 2017. Drug Safety Communication: FDA warns about rare but serious allergic reactions with the skin antiseptic chlorhexidine gluconate. 